\title{
Somatic Lexemes in the Kartvelian Linguistic Space
}

\author{
Rusudan Asatiani \\ Iv. Javakhishvili Tbilisi State University \\ Natia Dundua \\ Marine Ivanishvili \\ Ether Soselia
}

\begin{abstract}
Comparative-historical study of languages makes it possible to represent the diachronic process of structuring the world and forming the corresponding concepts. The abovementioned process is inherently integral and reflected in such socio-cultural areas of human life as language, art, religion, farming, ethno-traditional customs, culture (in its broadest sense), etc. The proto-language reconstructed as a result of the comparative-historical study and the picture of its diachronic development provide some information about the genetic relations between the people speaking the corresponding related languages, about their original homeland and the directions of their historical migrations, about their knowledge, ideas and representations. This time we have analyzed the semantic field of the lexemes denoting the human body parts, which are reconstructed at the ProtoKartvelian language and exist in the contemporary Kartvelian languages (Georgian, Megrelian, Laz, and Svan) and some dialects (notably, Gurian, Rachian, Xevsurian, and Kiziqian). Our goal is to reveal the semantic structure of the mentioned field, to analyze the respective concepts as well as to outline processes of the development and the establishment of corresponding tokens (resp. lexemes). Vocabulary denoting a human body (resp. Somatic lexemes), its parts and inner organs is a constituent part of the basic core vocabulary of a language and presumably ought to be fixed in the ancient times' reflecting data. Analysis of the lexical units, which have been reconstructed either at the Common-Kartvelian or Georgian-Zan level on the basis of regular sound correspondences between the Kartvelian languages, allows us to highlight the main course of forming and developing the linguistic units we are concerned with; namely, the accumulation of "knowledge" had been carried out due to the process of differentiation and detailed elaboration of the human body anatomy and respectively, the corresponding semantic field, somatic vocabulary, had been underway to be enriched based on the relation of cognitively interpreted markedness. Language changes and development, formation of new categories and concepts, and consequently, creation of new linguistic units is mainly carried out as the result of detailed elaboration, further specification and partition of unmarked categories: an unmarked category undergoes the division-differentiation on the basis of formally marked oppositions that leads to the formation of new linguistic units and structures and reflects the dynamic picture of enhancement of linguistic cognition of the universe. Dialectic material enriches the semantic space even more and specifies and fills the meanings of lexemes to be studied.
\end{abstract}

Keywords: Somatic Lexemes in the Kartvelian Linguistic Space

\section{Introduction}

„Ihre Verschiedenheit ist nicht eine von Schällen und Zeichen, sondern eine Verschiedenheit der Weltansichten selbst." Wilhelm von Humboldt

Language is one of the means of reflecting 'reality'. Reality is a whole that is structuralized according to specific linguistic structures. During the process of conceptualization various linguistic entities are defined as linguistic categories. This is a 
way of creating a specific linguistic picture of 'world view'. The main goal of linguistic studies is to 'discover' universal and specific features defining such processes. The goal can be achieved by the typological, cross-linguistic investigations based on the method of comparative linguistics. Comparison of languages traditionally gained ground along two directions: Diachronic (Comparative-historical linguistics) and Synchronic (Typological linguistics). Comparative-historical linguistics makes it possible to represent diachronic changes of conceptualization and linguistic structuring of reality. Changes of a language system mirror changes within various social-cultural spheres of human being such as art, religion, ethnic traditions, economy, civilization, culture, and so on. On the basis of the comparative-historical methodology, reconstructed proto-language and its diachronic development help us to get some information about the historical existence of the speakers, which includes the ecological environment (fauna, flora, geographic surrounding, climate) and human habitation, and migration in the environment as well as culture in the broadest sense (including both, material and spiritual culture).

\section{Defining objectives}

This time we are aimed at studying the semantic field of the lexemes denoting the human body parts reconstructed at the Kartvelian linguistic space. Vocabulary denoting a human body, its parts and inner organs is a constituent part of the basic core vocabulary of a language and presumably ought to be embedded in the ancient state reflecting data. Our goal is to reveal the semantic structure of the mentioned field (resp. Somatic vocabulary) and to analyze the respective organizing concepts. The research is based on the data presented in the Etymological Dictionary of the Kartvelian languages (Heinz Fähnrich, Zurab Satjveladze, Tbilisi: TSSOS Un. Press. 2000)

\section{Main tasks}

Our main tasks are: Forming the Corpus of target data; Systematizing and grouping the data according to the Gerhard Deeters's scheme of the diachronic development of the Kartvelian languages:

Comparing the Common-Kartvelian and Common Georgian-Zan reconstructed lexical entities in order to reveal the mainstream of diachronic processes reflecting the human body parts conceptual articulation and new terms formation; Generalizing observations and offering some possible theoretical interpretation of linguistic tendencies and regularities;

Answering the question: What did a human being "look like" in the Kartvelian linguistic space?

IVa. The data: Common-Kartvelian linguistic space

On the basis of sound correspondences existing between the all Kartvelian languages 17 lexemes are reconstructed at the Common-Kartvelian level which represent the following concepts corresponding to the human body parts:

ARMPIT, EYE, FACE/MOUTH, FOREHEAD, GENITALIS (MAN), HAIR, HAND, HEAD, LEG, NECK, NOSE/NOSTRIL, PENIS, (EYE) PUPIL, RIGHT-HAND, SHOULDER, TONGUE, VEIN.

If some sound correspondences between Georgian and Svan are taken into account and, respectively, are reconstructed for the Common-Kartvelian level the following concepts can be added to the above given list as well:

EYE (VISIBLE), CROWN (OF HEAD), CHEEK, CHEEK (ROCKY), CHIN, PENIS, LARYNX, LEG, JAW, EAR, FOREHEAD, CALF.

Thus, totally, there are 25 concepts that are realized by 29 lexemes, among which 4 entities marked by red color have doublet forms.

IVb. The data: Common-Georgian-Zan linguistic space

Sound correspondences existing between the Georgian and Zan languages make us possible to reconstruct 28 additional concepts reflecting the human body parts terms:

ARM/BONE, BEARD/POINT, BOSOM, BREAST (OF WOMAN), CALF, CHIN, EAR, ELBOW, EYEBROW, FINGER, FINGERNAIL/TOENAIL, GUM, (THICK) HAIR, HEAD, HEEL, HUMP/BIG STOMACH, (ANAT.) JOINT, KNEE, LARINX, LIP, LITTLE FINGER/TOE, NAVEL, NOSE/BILL, PENIS, THIGH (INNER SIDE), THROAT, TOOTH, WINDPIPE.

\section{Some observations}


The data analysis shows more (compared to the Common-Kartvelian data) detailed description of human body; especially, the further articulation of the area of LARYNX: WINDPIPE, THROAT, LARYNX, and others; Differentiation of MAN and WOMAN organs: BOSOM/CHEST/BREAST WOMAN BREAST; The doublet lexemes reveal different origins of body part terms formation; e.g.: NOSE $\leftarrow$ NOSTRIL//NOSE $\leftarrow B I L L, ~ B E A R D \leftarrow B E A R D ~ P O I N T$.

\section{Conclusions: generalization and theoretical interpretation}

Analysis of the lexical units, which have been reconstructed either at the Common-Kartvelian or Georgian-Zan level on the basis of regular sound correspondences between the Kartvelian languages, allows us to highlight the main course of forming and developing the linguistic units we are concerned with; Namely, the accumulation of "knowledge" had been carried out due to the process of differentiation and detailed elaboration of the human body anatomy and, respectively, the corresponding semantic field (resp. somatic vocabulary) had been underway to be enriched based on the relation of cognitively interpreted markedness.

Language changes and development, formation of new categories and concepts, and consequently, creation of new linguistic units is mainly carried out as the result of detailed elaboration, further specification and partition of unmarked categories; An unmarked category undergoes further division-differentiation on the basis of distinguishing cognitively marked categories and establishing formally marked oppositions. The process leads to the formation of new linguistic units and structures and reflects the dynamic picture of enhancement of linguistic cognition of the universe.

\section{What did a human being "look like" in the Kartvelian linguistic space?}

\section{Project: "Main models of information structures in the Georgian dialects: Gurian, Rachian, Xevsurian, Kiziqian" (2016-2019)}

The main goal of the project is to investigate information structures in Georgian dialects. Eight field sessions were organized in regions of Racha and Guria (Summer, 2017) and Kiziqi and Xevsureti (Summer, 2018). The spoken texts corpora were created on the basis of experimental tasks.

Gurian: Parallel form for Standard Language lexemes:

lak'ap'urči loq'a-"cheek"; p'op'ori t'uči-"lip"; c'imk'ina lavic"i-"collar-bone"; čimčimi tvalis up'e-"eye socket"; čmp'o үip'i-"(pot) belly"; q'ia k'iseri-"neck"

Specific forms of lexemes (arisen as a result of phonetic processes characteristic for the dialects):

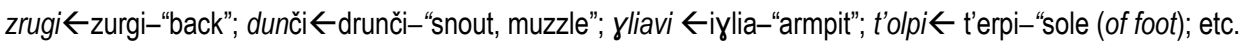

Derivatives:

amo-čagvi-eb-a-"putting (sth.) under one's arm"; ga-k'uč'-eb-a-"getting angry"; mo-k'ut'ur-eb-a-"loading (onto back); etc.

Racha: Parallel forms for Standard Language lexemes:

k'ančaya k'anč'i-"lower leg, shin"; k'onk'oraxi k'epa - "back of (human) head"; k'unsubo k'udusuni - "back of (human) head"; q'iq'ap'o yababi - "double-chin"

Specific forms of lexemes (arisen as a result of phonetic processes characteristic for the dialects):

k'lavi «mk'lavi -"arm"; ulaši Łulvaši - "moustache"; paši $\leftarrow$ pašvi - "paunch"; pxari $\leftarrow$ mxari - "shoulder"; xirximali<xerxemali - "spinal column"; etc.

Derivatives:

a-k’ančur-eb-a-"lifting of painful leg"; a-čliav-eb-a - "carries smth. under one's arm; mo-byunz-ul-i-"bent"; p'iraoši - "saying (sth) to sb's face"; etc.

Xevsureti: Parallel forms for Standard Language lexemes:

kuri loq'a-"cheek"; qint'o nest'o-"nostril"; č'ip'č'ora č'ip'i-“navel"; q'inčara // q'iranča q'anq'rat'o-"windpipe". 
Specific forms of lexemes (arisen as a result of certain phonetic processes characteristic for the dialects):

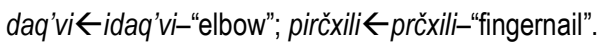

Derivatives:

sa-lak'-e-"sole (of foot)"; sa-varcx-al-i-"back part of foot/hand"; sazalt'e maža-"wrist"; sa-lik'-a-"index finger".

Kiziqian: Parallel forms for Standard Language lexemes:

batki t'erpi-"sole (of foot); bolkveni bokveni-"small stomach below navel"; iogio k'ut'(u)-"pennis"; yinci k'iseri-"neck".

Specific forms of lexemes (arisen as a result of certain phonetic processes characteristic for the dialects):

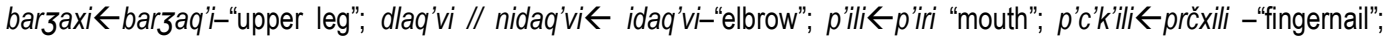
člink'i $\leftarrow$ člik'i//čliki "front part of foot".

\section{Conclusions:}

Only few really new Somatic Terms were documented in the dialects reflecting further, more concrete lexicalization of human body parts.

Rachian: mk'vlivi-"bone of calf"; $\gamma$ virk"i-"back part of knee"; člizvi-"back part of shin";

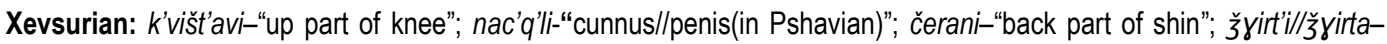
"solidified flesh between a flesh and a skin";

Kiziqian: k'enxa-"the crown (part of skull covered with hear); k'ubača, k'uk'uznak'i-"the bone where vertebra is located"; mqrik'ic"i-"the part of body where shoulder meets arm"; sasalak"i-"hanging part of soft palate"; $t^{\prime \prime l a q ' v i-" t h e ~ n a k e d ~ l e g ~ w i t h ~}$ rump(in poetry)"; t'ut'ua- "girl's sexual organ"; čana- "low part of jaw"; č'izvi-"the shoulder's joint".

All other specific lexemes have arisen either as a result of certain phonetic processes characteristic for these dialects or, having an absolutely new forms, have given dialectic doublet lexemes for the Standard Georgian terms.

Sometimes the lexical meaning of a somatic term varies slightly; e.g., in Xevsurian: gvami "body=corpse(SG)"; ku(r)sli "sole=heel(SG)"; ć'ip'i "paunch=navel(SG)"; q'ba "beard=jaw(SG)".

Derivatives make a productive device for a generation of new lexical, especially, emotionally "colored" units.

\section{Bibliography}

[1] Dzidziguri S., rač'uli dialekt'i, Tbilisi 1970.

[2] Imnaishvili Gr., guruli dialekt'i, Tbilisi 2006.

[3] Jajanidze P., guruli dialekt'i, I, Tbilisi 1977.

[4] Jankarashvili L., rač'uli k'ilos gloluri met'q'veleba, TSU, Tbilisi 1960, pp. 120-121.

[5] Kobadze M., gurulis ponet'ik'uri da morpologiur-sint'aksuri taviseburebani, TSU 8, Tbilisi 1958.

[6] Menteshashvili S., kiziq'uri leksik'oni, Tbilisi 1943.

[7] Rač'uli dialekt'is leksik'oni (ed. Al. Kobakhidze), Tbilisi 1987.

[8] Shanidze Ak., kartuli k'iloebi mtaši, TSU, Tbilisi 1984.

[9] Sharashidze G., guruli leksik'oni, Tbilisi 1938.

[10] Tchankvetadze L., rač'uli leksik'a zemo rač'isa da mtarač'is met'q'velebis mixedvit, TSU, Tbilisi 1960, p. 119.

[11] Tchintcharauli Al., xevsurulis taviseburebani, Tbilisi 1980.

[12] Uturgaidze T. (ed.), rač'uli (gloluri) t'ekst'ebi, Tbilisi 1991.

[13] Zhghenti S., guruli k'ilo, Tbilisi 1936. 